\title{
ANÁLISE DE RISCO E RETORNO DO SETOR FLORESTAL: PRODUTOS DA MADEIRA $^{1}$
}

Rommel Noce ${ }^{2}$, Márcio Lopes da Silva ${ }^{3}$, Thelma Shirlen Soares ${ }^{4}$ e Rosa Maria Miranda Armond Carvalho ${ }^{4}$

\begin{abstract}
RESUMO - O presente trabalho objetivou descrever, analisar e comparar a relação risco/retorno dos produtos madeira serrada, madeira aplainada, madeira laminada, compensado e pasta química de madeira em função do comportamento de seu preço, durante as três últimas décadas, com base na taxa geométrica de crescimento e na dispersão dos preços. De acordo com os resultados, concluiu-se que os únicos produtos que apresentaram relação favorável à captação de recursos durante essas três décadas foram madeira serrada e madeira aplainada.
\end{abstract}

Palavras-chave: Atividade madeireira, economia florestal, risco e retorno financeiro.

\section{ANALYSIS OF RISK AND RETURN OF THE FOREST SECTOR: WOOD PRODUCTS}

\begin{abstract}
This work aimed to describe, analyze and to compare the relation risk and return of the forest products: sawn wood, planed wood, veneer, plywood and the chemical pulpwood, in function of the behavior of its price, during the three last decades with base in the geometric rate of growth and in the price dispersion. The results indicated that the only products that presented favorable relation to fund raising, during the three decades, were the sawn and planed wood.
\end{abstract}

Words-key: Logger activity, forest economy, risk and financial return.

\section{INTRODUÇÃO}

Atualmente, constata-se o crescente destaque do setor florestal brasileiro para a economia nacional. Assistese por todo o mundo, em diferentes tipos de organizações, o surgimento de um interesse renovado pelas atividades florestais, das quais se destaca a produção madeireira.

A atividade florestal tem crescido no mundo inteiro. Prova disso é o crescente comércio de produtos florestais entre os diversos países, em que a indústria de produtos florestais representa, aproximadamente, $3 \%$ do PIB mundial (BEST e JENKINS, 1999).

A produção mundial de madeira para todos os fins aproxima-se de 3,3 bilhões de $\mathrm{m}^{3}$ por ano. Seis países produzem mais da metade de toda a madeira do mundo: Estados Unidos, China, Índia, Brasil, Indonésia e Canadá. O Brasil é o quarto maior produtor mundial de madeira, participando com $6 \%$ do total (TORESAN, 2002).

Nesse contexto, constata-se o crescente destaque do setor florestal brasileiro na economia nacional, com

\footnotetext{
${ }^{1}$ Recebido em 14.11.2002 e aceito para publicação em 25.11.2004.

${ }^{2}$ Programa de Pós-Graduação em Ciência Florestal. Universidade Federal de Viçosa. 36570-000 Viçosa, MG.

${ }_{3}^{3}$ Departamento de Engenharia Florestal da Universidade Federal de Viçosa. Viçosa, MG. E.mail: <marlosil@ ufv.br> .

${ }^{4}$ Programa de Pós-Graduação em Ciência Florestal. Universidade Federal de Viçosa. Viçosa, MG.
} 
um PIB florestal de aproximadamente US\$ 21 bilhões, com exportações de US\$ 4 bilhões, no ano de 2001 (SBS, 2002).

A geração de 2 milhões de empregos (diretos e indiretos) demonstra a importância social do setor florestal, que também é relevante em relação aos impostos recolhidos, em torno de US\$ 3 bilhões anuais. Para a Sociedade Brasileira de Silvicultura (SBS, 2002), o potencial do Brasil, que possui a segunda maior cobertura florestal do mundo, é ultrapassar US\$ 11 bilhões com vendas externas, em 2010.

O risco, em seu sentido fundamental, é a possibilidade de prejuízo financeiro ou, mais formalmente, a variabilidade de retornos associada a determinado ativo. Assim, a relação risco/retorno desempenha papel preponderante na determinação do destino dado ao capital privado, de forma que um dos principais atrativos para o investimento é uma relação coerente entre essas duas variáveis (GITMAN, 2004).

Considerando que a atividade florestal requer investimento intensivo em terra e capital, apresentando baixas taxas iniciais de retorno devido ao lento crescimento da floresta, possibilitando a recuperação de capital apenas no longo prazo, torna-se necessário conhecer o comportamento da relação risco/retorno dos produtos da madeira, diante da sua implicação para a alocação futura de recursos no setor.

Associando o comportamento dos preços ao crescimento florestal, é possível o setor competir, dentre outras opções de investimento, pela captação de recursos. Assim, os objetivos deste estudo foram descrever, analisar e comparar a relação risco/retorno da madeira serrada, aplainada e laminada, além do compensado e da pasta química de madeira, em função do comportamento de seus preços durante o período de janeiro de 1970 a dezembro de 1996.

\section{MATERIAL E MÉTODOS}

Foram geradas séries históricas de preços com periodização mensal, com dados obtidos na Secretaria de Comércio Exterior (SECEX). Estas séries foram corrigidas em função da sazonalidade e filtradas, gerando os primeiros resultados que expressaram graficamente o comportamento dos preços.

A partir das séries de preço foi possível calcular a taxa de crescimento geométrico e o desvio-padrão dos preços de cada produto. Esses indicadores foram organizados em novas séries, gerando o segundo resultado, o comportamento do risco (desvio-padrão) e retorno (taxa de crescimento geométrico) de cada produto.

Foram calculadas as médias das taxas de crescimento e das dispersões dos preços de cada década, o que possibilitou demonstrar graficamente a evolução do risco e do retorno entre esses anos. Através dessas médias foi realizada a comparação entre os produtos em cada década do período analisado, por meio de gráficos de dois eixos: risco (eixo X) e retorno (eixo Y).

Utilizou-se a série de preço FOB em dólar da madeira serrada, aplainada e laminada, do compensado e da pasta química de madeira em série mensal, no período de 1970 a 1996, corrigidos através da sazonalidade e filtrados segundo a metodologia proposta por Hodrick e Prescott (1997), gerando as linhas de tendência.

A Figura 1 ilustra os passos seguidos na metodologia deste trabalho.

O risco relativo a cada um dos produtos foi estimado através do desvio-padrão anual, convertido em índice de base $1996=1$ para todos os produtos para que a diferença de valor unitário entre estes não distorcesse os resultados. O retorno foi estimado através da taxa de crescimento geométrico anual.

O cálculo das taxas geométricas de crescimento foi realizado com a utilização do software E-Views 3.0 e determinado, estatisticamente, por regressão linear de tendência, através da seguinte expressão:

$\log Y=a+b T$

em que:

$\mathrm{Y}=$ preço em US\$;

$a=$ constante da regressão;

$\mathrm{b}=$ coeficiente da regressão; e

$\mathrm{T}=$ tendência.

Para valores de "b" significativamente diferentes de zero, calculou-se a taxa geométrica de crescimento pela fórmula:

$A N T \log b=1+T G C$, sendo $T G C=(A N T \log b-1) \times 100$.

A evolução foi observada em gráfico de série temporal, enquanto a comparação, realizada plotandose os pares ordenados (risco; retorno) de cada produto nos eixos X e Y para cada década. Fez-se uso do Microsoft Excel e do software Econometric Views para a execução de todos os tratamentos de dados e demonstrações. 


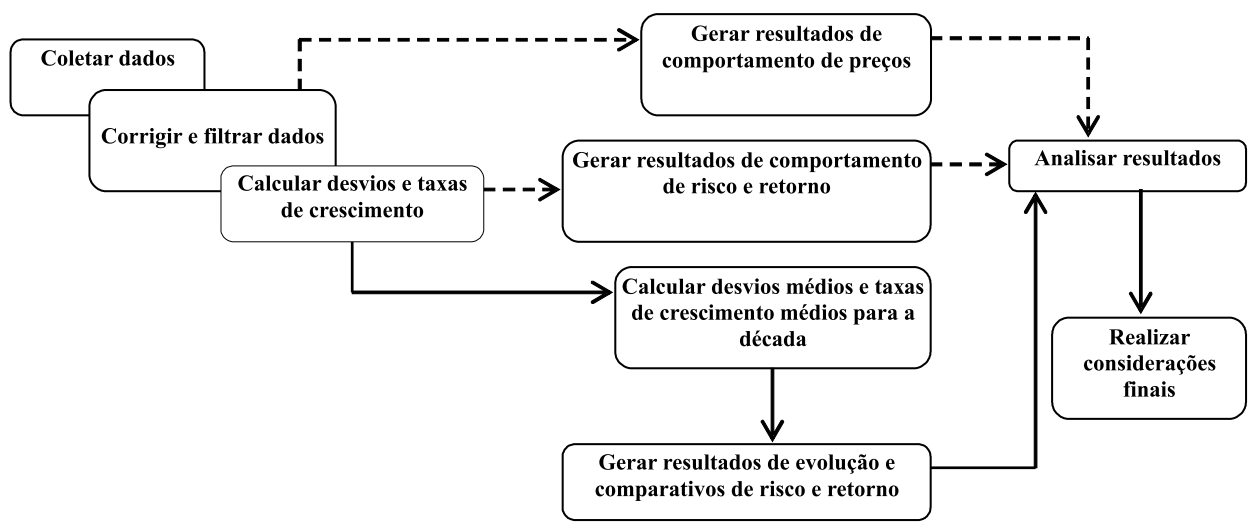

Figura 1 - Fluxograma das atividades desenvolvidas. Figure 1 -Flowchart of the developed activities.

\section{RESULTADOS E DISCUSSÃO}

\subsection{Comportamento dos preços 1970 - 1996}

O comportamento dos preços dos produtos analisados é representado na Figura 2, no período de 1970 a 1996, em série mensal. As séries foram corrigidas pelos respectivos índices de sazonalidade e geraram curvas de tendência.

O preço da pasta química de madeira inicia na década de 1970, com tendência decrescente; a partir de 1972, assume tendência crescente até 1981 , e a tendência passa a ser decrescente até 1985 , assumindo comportamento cíclico a partir de então.

Os preços do compensado no período analisado apresentaram tendência crescente do início da década de 1970 até 1981 , em função de comportamento cíclico decresce até 1984, retomando a tendência de crescimento que se apresentou praticamente linear na década de 1990.

Os valores de preço observados da madeira aplainada apresentaram tendência crescente até 1975, quando assumiram comportamento cíclico também crescente, que foi suavizando até tornar-se praticamente linear e crescente durante a década de 1990.

A madeira laminada apresentou uma série de preços com comportamento de tendência cíclico, observandose, porém, que os ciclos se tornaram cada vez mais longos e com ápices cada vez menores, de forma que a linha de tendência foi suavizando, o que indica oscilação menor nos preços.
Em relação à madeira serrada, a tendência dos preços foi crescente até 1981, quando assumiu comportamento cíclico com ligeira tendência decrescente no fím do período analisado.

\subsection{Comportamento Risco e Retorno}

Espera-se que um investimento atrativo ao capital privado apresente taxas de risco e retorno que ao menos cresçam e decresçam de forma simétrica. Observamse, na Figura 3, os comportamentos das taxas de risco e retorno dos produtos analisados no período de 1970 a 1990.

Observa-se que a madeira laminada apresentou as curvas de desvio e taxa de crescimento dos preços, comportando-se de forma simétrica nos períodos de 1970 a 1974; 1976 a 1982; 1985 a 1987; e 1989 a 1996. As curvas se mostraram assimétricas nos períodos de 1974 a 1976; 1982 a 1985; e 1987 a 1989. Nos períodos em que as curvas foram assimétricas, têm-se aquelas em que o desvio foi diminuindo e a taxa de crescimento aumentando de 1974 a 1976 e de 1983 a 1985 . Essa situação é favorável à atividade e, portanto, pode ocorrer sem acarretar problemas. A situação se agravou nos períodos em que o risco, ou desvio, aumentou e a taxa de crescimento caiu, como de 1982 a 1983 e de 1988 a 1989. Esses períodos foram críticos, pois refletiram um comportamento que não fez sentido para os investidores, sendo uma assimetria desfavorável.

Notou-se que em relação à madeira aplainada as curvas de desvio e da taxa de crescimento dos preços comportaram-se de forma simétrica nos períodos de

R. Árvore, Viçosa-MG, v.29, n.1, p.77-84, 2005 
1970 a $1971 ; 1972$ a $1974 ; 1980$ a $1984 ; 1986$ a $1978 ;$ 1988 a 1989; e de 1991 a 1996 . As curvas se mostraram com assimetria favorável nos períodos de 1974 a 1976;
1978 a 1980; 1984 a 1985; 1989 a 1990 e assimetria desfavorável em 1971 a 1972; 1976 a 1978; 1987 a 1988; e de 1990 a 1991.
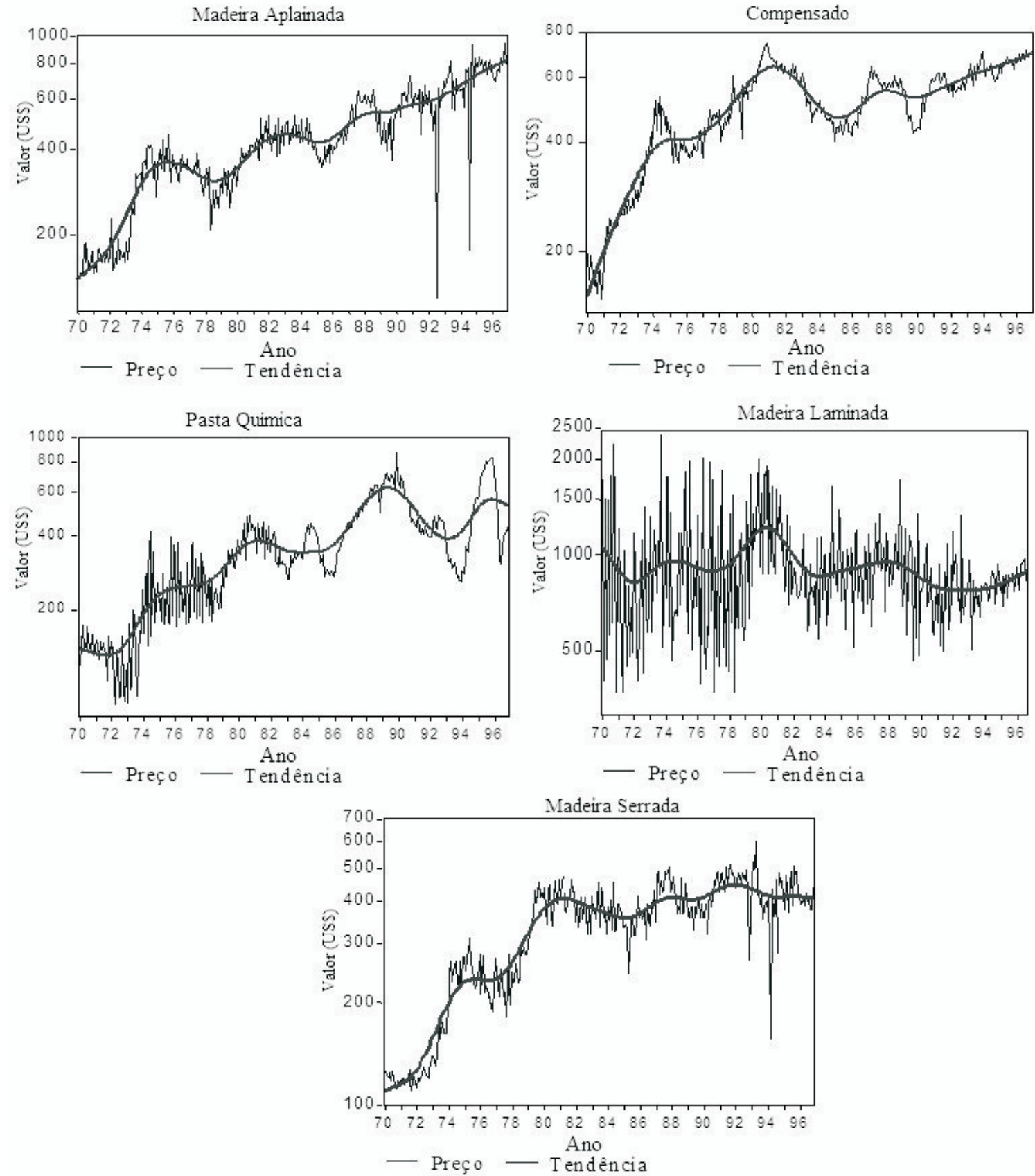

Figura 2 - Comportamento do preço no período de 1970 a 1996.

Figure 2 - Behavior of the price in the period from 1970 to 1996.

R. Árvore, Viçosa-MG, v.29, n.1, p.77-84, 2005 

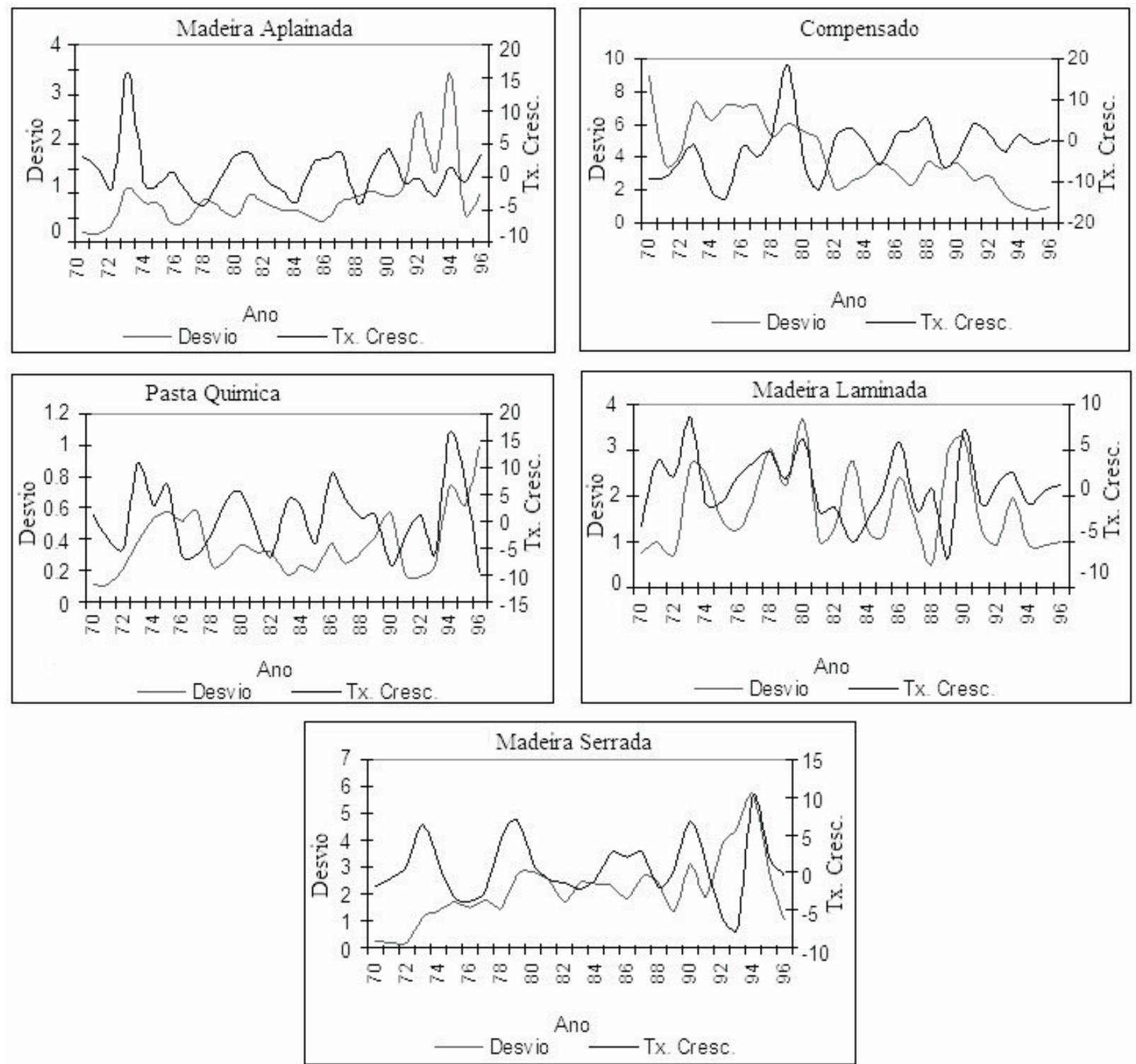

Figura 3 - Comportamento do desvio-padrão e das taxas de crescimento geométrico no período de 1970 a 1996. Figure 3 -Behavior of the standard deviation and of the geometric growth rates in the period from 1970 to 1996.

Verificou-se que as curvas de desvio e taxa de crescimento dos preços do compensado comportaramse de forma simétrica nos períodos de 1971 a 1975 ; 1978 a $1981 ; 1982$ a $1983 ; 1987$ a $1990 ; 1992$ a 1993 ; e de 1994 a 1996. Mostraram-se com assimetria favorável nos períodos de 1970 a 1971; 1975 a 1976; 1977 a 1978; 1981 a 1982 ; 1985 a $1987 ; 1990$ a $1991 ; 1993$ a 1994 e assimetria desfavorável em 1976 a 1977; 1983 a 1985; e 1991 a 1992.

Em relação à pasta química de madeira, notouse que as curvas de desvio e taxa de crescimento dos preços comportaram-se de forma simétrica nos períodos de 1972 a 1973 ; 1974 a 1977; 1978 a $1981 ; 1984$ a 1987 ; 1988 a 1989; 1991 a 1992; e de 1993 a 1995. As curvas

R. Árvore, Viçosa-MG, v.29, n.1, p.77-84, 2005 
se mostraram com assimetria favorável nos períodos de 1977 a 1978; 1982 a 1983; 1990 a 1991 e assimetria desfavorável em 1970 a 1972; 1973 a 1974; 1981 a 1982; 1983 a $1984 ; 1987$ a $1988 ; 1989$ a $1990 ; 1992$ a 1993 ; e 1995 a 1996.

As curvas de desvio e taxa de crescimento dos preços da madeira serrada comportaram-se de forma simétrica nos períodos de 1972 a $1973 ; 1975$ a 1977 ; 1978 a $1979 ; 1980$ a $1982 ; 1985$ a $1988 ; 1989$ a $1991 ;$ e de 1993 a 1996. Mostraram-se com assimetria favorável nos períodos de 1970 a 1971; 1977 a 1978; 1983 a 1985; 1988 a 1989 e assimetria desfavorável em 1973 a 1975; 1979 a $1980 ; 1982$ a 1983 ; e 1991 a 1993.

\subsection{Evolução do risco e retorno}

Nota-se, na Figura 4, a evolução dos níveis de risco e retorno para cada produto ao longo das três décadas do período em análise.
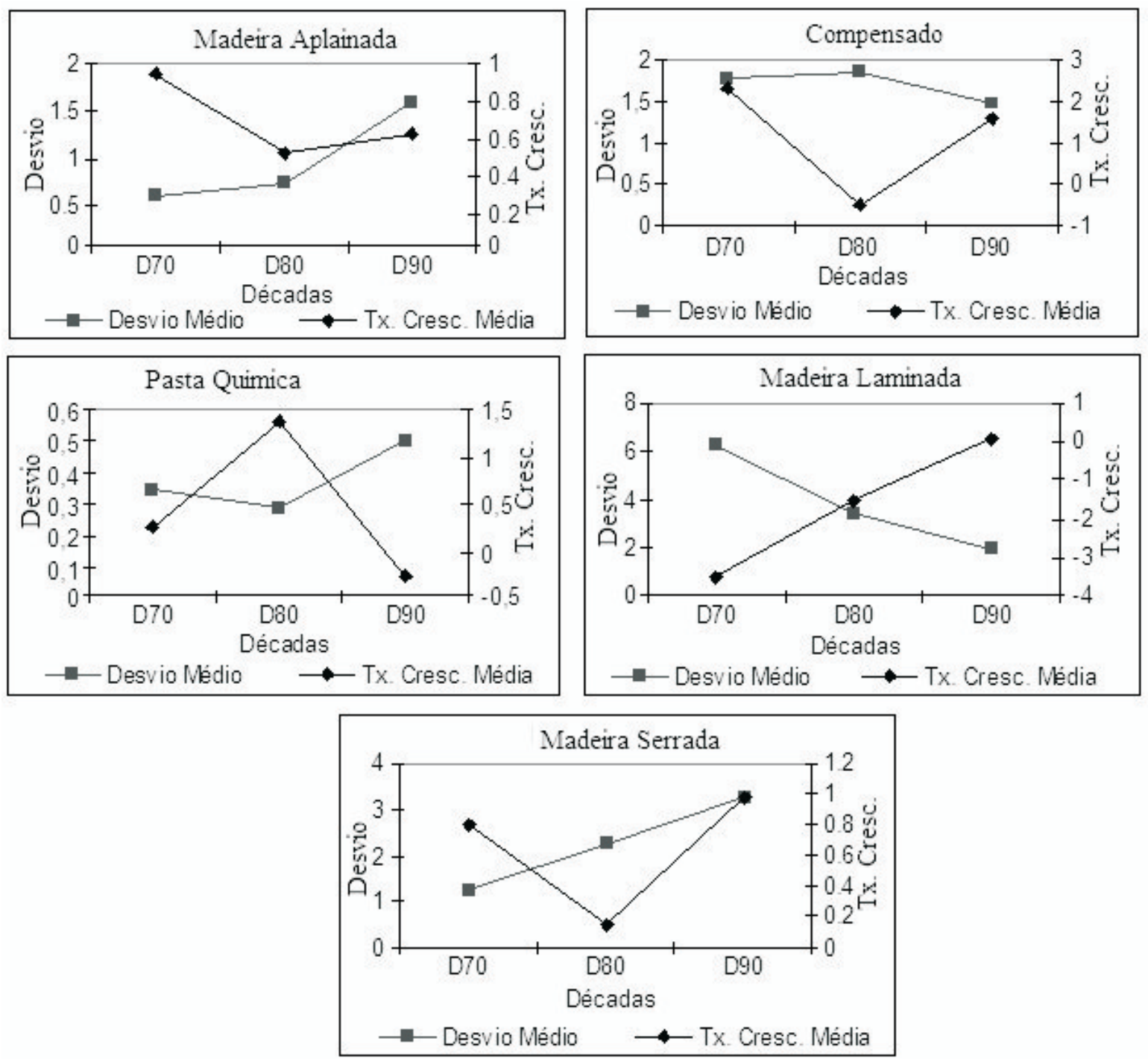

Figura 4 - Evolução do risco e retorno nas décadas de 1970, 1980 e 1990.

Figure 4-Evolution of the risk and return in the decades of 1970, 1980 and 1990.

R. Árvore, Viçosa-MG, v.29, n.1, p.77-84, 2005 
Quanto à madeira laminada, a dispersão média dos preços reduziu sucessivamente nas décadas de 1980 e 1990, se comparada com a da década de 1970. De forma análoga, a taxa de crescimento, negativa nas décadas de 1970 e 1980, evoluiu até um valor positivo na década de 1990.

Da década de 1970 para 1980, observaram-se uma queda considerável na taxa de crescimento e um pequeno aumento na dispersão dos preços da madeira aplainada, já na década de 1990 ambos aumentaram, porém a dispersão média teve aumento relativamente maior.

Em relação aos preços do compensado, ocorreu pequeno aumento na dispersão durante a década de 1980 , porém a queda na taxa de crescimento foi muito significativa. Na década seguinte, notou-se pequena qued na dispersão com uma recuperação de boa parte da redução sofrida pela taxa de crescimento.

Em termos médios, a pasta química de madeira apresentou um substancial aumento da taxa de crescimento e pequena diminuição na dispersão dos preços na década de 1980; já nos anos de 1990 a taxa de crescimento média apresentou valor negativo, e a dispersão média atingiu valor superior ao observado na década de 1970.

A dispersão dos preços da madeira serrada aumentou em termos médios praticamente de forma linear ao longo das últimas três décadas. Enquanto a taxa de crescimento reduziu significativamente nos anos de 1980 , recuperando-se na década de 1990 para um valor superior ao observado nos anos de 1970.
A madeira serrada, aplainada e o compensado apresentaram redução nas taxas de crescimento diante dos aumentos de dispersão na década de 1980, com posterior incremento da taxa de crescimento nos anos de 1990. A madeira laminada veio aumentando a taxa de crescimento e reduzindo a dispersão ao longo das décadas, enquanto a pasta química de madeira aumentou a taxa de crescimento e diminuiu a dispersão na década de 1980 e, durante a de 1990, apresentou queda na taxa de crescimento e aumento na dispersão dos preços, ao contrário dos demais produtos analisados.

\subsection{Comparação das taxas de risco e retorno}

Para uma atividade atrair recursos é necessário, "a priori", que esta apresente relação positiva entre suas taxas de risco e retorno. Na Figura 5 são representadas as relações risco/retorno dos cinco produtos analisados de cada uma das décadas de 1970 a 1996.

Observou-se na década de 1970 que o retorno da pasta química de madeira encontrava-se próximo de zero, enquanto a madeira aplainada e a madeira serrada apresentaram tanto taxas de retorno quanto de risco superiores, sendo a taxa de retorno bem próxima para os dois produtos quanto para a madeira serrada apresentando risco maior. Já o compensado apresentou tanto o retorno quanto o risco, em níveis bem mais elevados; dos produtos analisados, apenas a madeira laminada teve relação negativa entre risco e retorno com o maior valor de risco observado e retorno negativo.

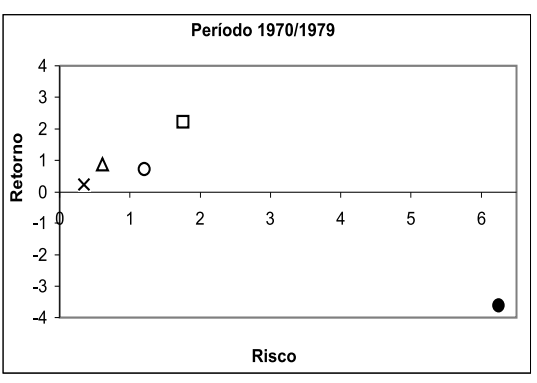

$\times$ Pasta Quimica

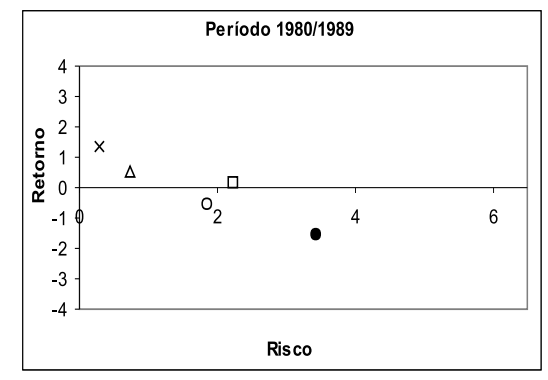

$\Delta$ Madeira Serrada

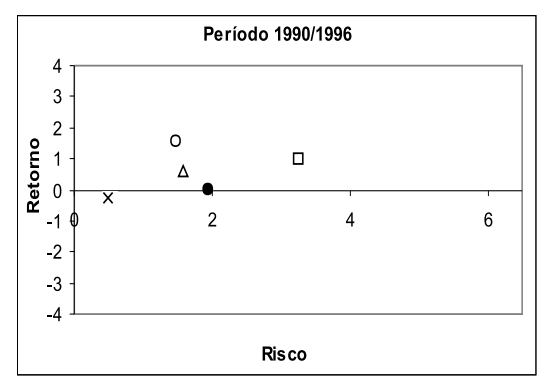

- Madeira Aplainada

Figura 5 - Comparação do risco e retorno nas décadas de 1970, 1980 e 1990.

Figure 5 - Comparison of the risk and return in the decades of 1970, 1980 and 1990. 
A média dos valores observados durante a década de 1980 apresentou a madeira laminada ainda com relação negativa entre risco e retorno, porém com menor risco e retorno mais próximo de zero. O compensado, que na década anterior apresentou o maior nível médio de retorno, mostrou-se com taxa de retorno negativa. A madeira aplainada sofreu aumento de risco relativamente pequeno se comparado ao da madeira serrada, notandose em ambos os produtos redução do retorno, em que a madeira serrada apresentou retorno próximo de zero. A pasta química exibiu comportamento semelhante ao da madeira laminada, reduzindo o risco e aumentando o retorno, porém, como apresentava relação positiva entre o risco e o retorno, atingiu a maior taxa de retorno entre os produtos e o menor risco.

Nos anos de 1990, a madeira laminada apresentou a recuperação - não mais possuía relação negativa risco/retorno -, e o índice de retorno foi praticamente nulo, porém positivo. A pasta química, que vinha progredindo em relação ao retorno, apresentava-se com taxa de crescimento negativa e, por conseqüência, relação negativa entre risco/retorno. Os demais produtos tiveram recuperação da taxa de retorno deteriorada nos anos de 1980 e o compensado assumiu a maior taxa de retorno e o segundo menor risco, dentre os produtos analisados. A madeira aplainada apresentase com taxas superiores de risco e inferiores de retorno, se comparadas com a da década de 1970, enquanto a madeira serrada exibia tanto maior risco quanto retorno.

Ao longo das três décadas, somente dois produtos não apresentaram relações negativas entre risco e retorno: a madeira aplainada e a serrada, com a ressalva de que esta última apresentou sempre maior risco.

\section{CONCLUSÃO}

De acordo com os resultados e nas condições em que foi desenvolvido este estudo, concluiu-se que:

- Ocorreu deterioração da relação risco/retorno, da década de 1970 para a de 1980, dos seguintes produtos: madeira serrada, madeira aplainada e compensado, que podem ser associados à instabilidade macroeconômica do período. O impacto foi mais forte no compensado, que passou a apresentar relação negativa entre risco e retorno. Posteriormente, na década de 1990 esses produtos recompuseram sua relação risco/ retorno.

R. Árvore, Viçosa-MG, v.29, n.1, p.77-84, 2005
- A pasta química de madeira comportou-se de maneira inversa; na década de 1980, a relação risco/ retorno melhorou bastante para se deteriorarem até valores negativos na década de 1990 , fato que pode ser associado ao surgimento de novos concorrentes no mercado internacional. Já a madeira laminada melhorou gradativamente a relação risco retorno até tornar-se positiva nos anos de 1990.

- Os únicos produtos que apresentaram relação coerente entre o risco e o retorno, ao longo de todo o período analisado, foram a madeira serrada e a madeira aplainada. Dessa forma, verificou-se que a evolução do risco/retorno é bastante distinta entre os produtos, destacando-se a madeira serrada e a aplainada como as mais atrativas ao capital privado, quanto ao risco e ao retorno.

\section{REFERÊNCIAS BIBLIOGRÁFICAS}

BEST, C; JENKINS, M. Opportunities for investment: capital markets and sustainable forestry. Washington: The Pacific Forest Trust, 1999. $80 \mathrm{p}$.

GITMAN, L. J. Princípios de administração financeira. 10. ed. São Paulo: Habra, 2004. 776 p.

HODRICK, R. J.; PRESCOTT, E. C. Postwar U.S. business cycles: an empirical investigation. Journal of Money, Credit, and Banking, v. 29, n. 1, p.1-16, 1997.

TORESAN, L. Desempenho e competitividade do setor florestal brasileiro e catarinense. Disponível em: <http://www.icepa.com.br/agroindicadores/opiniao/ analise_florestal.htm> Acesso em: 10 maio 2002.

SOCIEDADE BRASILEIRADE SILVICULTURA. SBS. Setor florestal brasileiro. Disponível em: <http://www.sbs.org.br/estatisticas.htm>. Acesso em: 21 abril 2002.

SECRETARIADE COMÉRCIO EXTERIOR. SECEX. Indicadores e estatísticas. Disponível em: <http://www.desenvolvimento.gov.br/sitio/secex/ depPlaDesComExterior/indEstatisticas/ balComercial.php > . Acesso em: 11 outubro 2001 . 